\title{
Post-vomiting purpura
}

\section{Badrilal Meghwal', Manisha Balai ${ }^{2}$}

${ }^{1}$ Department of Pediatrics, RNT Medical College, Udaipur, Rajasthan, India, ${ }^{2}$ Department of Dermatology, RNT Medical College, Udaipur, Rajasthan, India

Corresponding author: Dr. Badrilal Meghwal, E-mail: drblmeghwal@gmail.com

Sir,

We report a case of 7-year-old female child who presented with multiple, asymptomatic, purpuric lesions over face after a single episode of forceful vomiting. On examination the lesions were purpuric but not palpable. They were localized to bilateral periorbital regions (Fig. 1), slightly extending to the cheeks. (Fig. 2). The child was otherwise healthy and there was no previous history of any similar lesions in the past in the patient or his family. There were no skin lesions elsewhere, including mucosa. There was no history of any trauma, fever and sun exposure. There was no history of drug intake.

Laboratory investigations including complete blood count, bleeding time, clotting time, and prothrombin time were normal. The lesions subsided without treatment within a period of seven days.

We present this case to highlight the rare but definite entity called post-vomiting purpura. Purpura/petechie around the eyelids are classically seen while performing the Valsalva manoeuvre, but in practice they are more likely after severe coughing or vomiting, and also described after endoscopy $[1,2]$. The aetiology is a sudden rise in the venous and capillary pressure in the head and neck caused by a rise in intrathoracic pressure during vomiting. The lesions are self-resolving and no specific intervention other than patient counseling is required $[3,4]$.

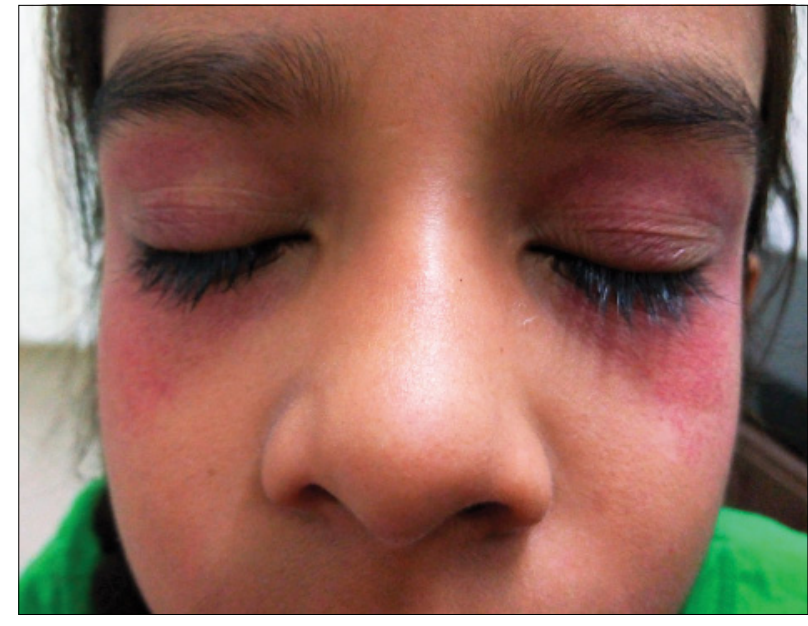

Figure 1: Purpuric lesions bilateral periorbital area after vomiting.



Figure 2: Left lateral view showing purpuric lesions extending to cheek. 
www.odermatol.com

\section{REFERENCES}

1. Kaliyadan F, Kuruvilla JP. Post-vomiting purpura. Indian Dermatol Online J. 2016;7:456-7.

2. Cox NH and Piette WW. Purpura and Microvascular Occlusion. In: Rook's Textbook of Dermatology. Burns T, Breathnach S, Cox N, Griffiths C editors. Blackwell Publishing; 2010. pp 49.4-5.

3. Burke M, Marks J. Purpura associated with vomiting in pregnancy. Br Med J. 1973;2:48.
4. Pitt PW. Purpura associated with vomiting. Br Med J. 1973;2:667.

Copyright by Badrilal Meghwal, et al. This is an open-access article distributed under the terms of the Creative Commons Attribution License, which permits unrestricted use, distribution, and reproduction in any medium, provided the original author and source are credited. Source of Support: Nil, Conflict of Interest: None declared. 